\title{
STUDIES ON MYCOBACILLIN DERIVATIVES
}

\section{ACETYL DERIVATIVES OF MYCOBACILLIN}

\author{
P.C. BANERJEe and S.K. Bose \\ Indian Institute of Experimental Medicine, Calcutta-32, India \\ and \\ Department of Biochemistry, University College of Science, Calcutta-19, India
}

(Received for publication September 8, 1972)

\begin{abstract}
Di- and triacetyl derivatives of mycobacillin, a cyclic peptide, have been prepared. Acetylation lowers its antifungal activity, the inhibitory concentration $(\mu \mathrm{g} / \mathrm{ml})$ for the diand triacetyl derivatives being $35 \sim 40$ and $40 \sim 45$ respectively as against $15 \sim 20$ for mycobacillin; but acetylation gives complete protection against serum inactivation of the antibiotic whose inhibitory concentration is increased tenfold in its presence.
\end{abstract}

Mycobacillin is a cyclic peptide antibiotic consisting of 13 residues of 7 different amino acids whose structure has been reported earlier ${ }^{1 \sim 4)}$. It is a broad-spectrum antibiotic and greatly inactivated in presence of serum which limits its possible use as a drug5). Now mycobacillin molecule (Fig. 1) contains many free reactive groups which may cause its inactivation by serum.

In the present work attempts were therefore made to study the effect of acetylation on its antifungal activity both in presence and absence of serum.

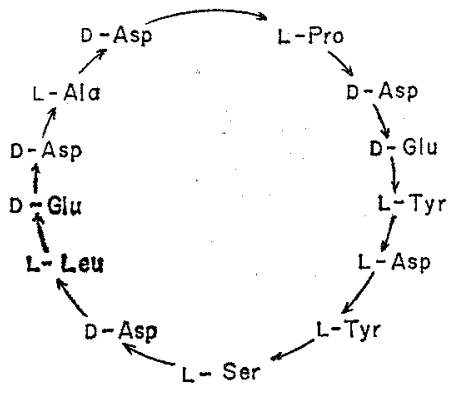

Fig. 1. Mycobacillin. $\rightarrow \mathrm{CO}-\mathrm{NH}$ linkage.

\section{Materials and Methods}

Mycobacillin was isolated from the culture filtrate of Bacillus subtilis $\left(\mathrm{B}_{3}\right)$ according to the method used by MAJUMder and Bose6).

A sensitive strain of Aspergillus niger $\left(\mathrm{G}_{3} \mathrm{Br}\right)$ was used as the test organism. For testing antifungal activity in absence of serum CZAPEK broth ( $\mathrm{pH} 6 \sim 6.5$ ) containing $20 \mu \mathrm{g}$ per $\mathrm{ml}$ each of penicillin and streptomycin was used and for the same in presence of serum was used CzAPEK broth (pH 6 6.5) containing all the ingredients in two-fold concentration and mixed with an equal volume of normal horse serum preincubated for 2 hours at $37^{\circ} \mathrm{C}$ with the antibiotics in two-fold concentration. Spore suspension $(0.05 \mathrm{ml})$ from 7 days old culture was added per $5 \mathrm{ml}$ of the medium. Mycobacillin and its derivatives were used in $60 \%$ ethanolic solution.

Preparation of diacetyl derivative: Diacetyl derivative at the two tyrosine hydroxyl groups of mycobacillin was prepared according to RIORDAN and VALLEE ${ }^{7}$. In practice, $88 \mathrm{mg}$ of mycobacillin was dissolved in $22 \mathrm{ml}$ of barbital sodium- $\mathrm{HCl}$ buffer $(\mathrm{pH} 7.4,0.02 \mathrm{M}$ ). Fifty fold molar excess of redistilled acetic anhydride $(0.5 \mathrm{ml})$ was added dropwise and the $\mathrm{pH}$ maintained within $7 \sim 7.5$ by automatic addition of $2 \mathrm{~N} \mathrm{NaOH}$. Reaction was carried out at $1 \sim 2^{\circ} \mathrm{C}$ in a Radiometer pH-stat. Acetylation was complete within 45 minutes as observed from the automatic titration curve. Acetyl mycobacillin so obtained was extracted with $n$-butanol and the extract washed thrice with a small volume of water, distilled under reduced pressure to a small volume, precipitated with ether and the 
precipitate washed twice with ether and centrifuged. The residue was dissolved in water, again centrifuged and the supernatant freeze-dried; yield $70 \mathrm{mg}$. Purity of the compound was tested by ascending paper chromatography in different solvent systems.

Preparation of triacetyl derivative: The tyrosine and serine hydroxyl groups were all acetylated by reaction of mycobacillin with acetic anhydride in presence of a basic catalyst pyridine. Mycobacillin $(100 \mathrm{mg})$ was dissolved in $10 \mathrm{ml}$ pyridine and then $15 \mathrm{ml}$ acetic anhydride added to it. Acetylation was found to be extremely slow at $37^{\circ} \mathrm{C}$. Only $20 \%$ of mycobacillin got acetylated in 24 hours at this temperature. But at $100^{\circ} \mathrm{C}$ (on boiling water bath) acetylation was almost complete within one hour. The reaction mixture was then cooled in ice-water bath to which was added excess of water. The derivative was extracted thrice with chloroform. Chloroform layer was washed thrice with water and then evaporated to a small volume and the concentrated extract precipitated with dry ether. The precipitate was dissolved in chloroform-methanol $(8: 2)$ and the solution precipitated with cold, dry ether. The process was repeated once more. Finally the derivative was crystallized from $95 \%$ methanol under reduced pressure over $\mathrm{P}_{2} \mathrm{O}_{5}$ in the cold. Purity of the derivative was tested by ascending paper chromatography using different solvent sys tems.

Paper chromatography: WhATMAN No. 1 paper was used for paper chromatography using the solvent systems:

1) $n$-Butanol-pyridne-water-acetic acid $(60: 40: 30: 3)$ and 2) $5 \% \mathrm{NH}_{4} \mathrm{Cl}$ in water for diacetyl derivative; and 1) $n$-butanol-pyridine-water-acetic acid $(60: 40: 30: 3), 2) t$-butanol-acetic acid- $\mathrm{H}_{2} \mathrm{O}$ $(55: 6: 4)$ and 3$) n$-butanol-acetic acid-water $(75: 10: 25)$ for triacetyl derivative.

Acid hydrolysis of mycobacillin and the triacetyl derivative: Acid hydrolysis was carried out at $105^{\circ} \mathrm{C}$ with conc. $\mathrm{HCl}$ for 18 hours (concentration $5 \mathrm{mg} / \mathrm{ml}$ ).

Determination of the extent of acetylation: Number of acetyl groups in the derivatives was estimated both by colorimetric ${ }^{8)}$ and spectrophotometric ${ }^{91}$ methods. By colorimetric method was determined the total number of hydroxyl groups acetylated, whereas by spectral method only the number of tyrosine hydroxyl groups acetylated. In practice, for colorimetric estimation, $2 \mathrm{ml}$ of $90 \%$ methanol containing $1 \sim 5 \mathrm{mg}$ of acetyl derivative was mixed with $0.6 \mathrm{ml}$ hydroxylamine reagent, kept for 30 minutes at room temperature and then $5 \mathrm{ml}$ of ferric perchlorate reagent added. Readings were taken after 10 minutes at $520 \mathrm{~m} \mu$ in a 'Bausch \& Lomb' spectronic 20 colorimeter against a blank containing all the materials in which hydroxylamine reagent was added after the addition of ferric perchlorate reagent. Moles of acetyl groups present per mole of mycobacillin was estimated from a standard curve prepared with $p$-nitrophenylacetate.

Spectral analysis was carried out by treatment of $2 \mathrm{ml}$ solution of the derivatives in $90 \%$ methanol with an equal volume of $2 \mathrm{~m}$ hydroxylamine in $90 \%$ methanol $(\mathrm{pH} 9.0)$ at room temperature for 2 hours and then the reaction mixture was made acidic with $1.0 \mathrm{ml}$ of $10 \% \mathrm{HCl}$. Readings were taken in the 'Uvispek' spectrophotometer. Moles of acetyl groups per mole of mycobacillin was calculated from the change in molar absorptivity with reference to O-acetyl tyrosine.

\section{Results}

\section{Properties of the Derivatives}

Both di- and triacetyl derivatives differ from mycobacillin in respect of solubility and absorption of light in the UV region. Mycobacillin is soluble in water at alkaline $\mathrm{pH}$ and almost insoluble in absolute alcohols, whereas the derivatives are readily soluble in absolute alcohols. Diacetyl derivative is also soluble in water both at acidic and alkaline $\mathrm{pH}$, but the triacetyl derivative is insoluble in dil. acid or alkali, but soluble in strong alkali $(0.4 \mathrm{~N})$. Triacetyl derivative is readily soluble in nonpolar solvent chloroform. Mycobacillin absorbs light in the UV region and has a peak at $272 \mathrm{~m} \mu$. This peak disappears totally in case of acetyl derivatives, but appears again when the derivatives are treated with hydroxylamine in alkaline pH (Fig. 2). 
The condition at which the triacetyl derivative has been prepared may lead to some keto group formation at the free $\alpha$-carboxyl groups of glutamic acid according to DAKIN and WEST reaction ${ }^{10,11}$. The derivative does not however respond to the iodoform and nitroprusside tests for ketones. That the derivative does not contain any keto group was further confirmed by the observation that the paper chromatogram of the acid hydrolysate of the derivative contains all the ninhydrin-positive spots as in the chromatogram of mycobacillin hydrolysate but no DNP-positive spot showing the absence of keto group (Fig. 3).

Extent of Acetylation.

Fig. 2. Effect of hydroxylamine on UV absorption spectra of O-acetyl derivatives of mycobacillin and tyrosine

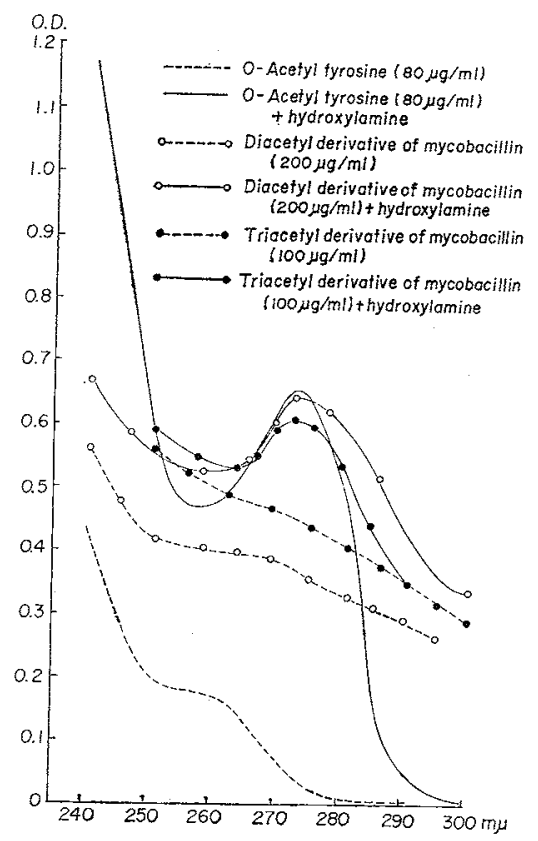

Fig. 3. Descending paper chromatogram of acid hydrolysates of mycobacillin and its triacetyl derivative. Solvent system: $n$ butanol-pyridine-water-acetic acid $(60: 40: 30: 3)$

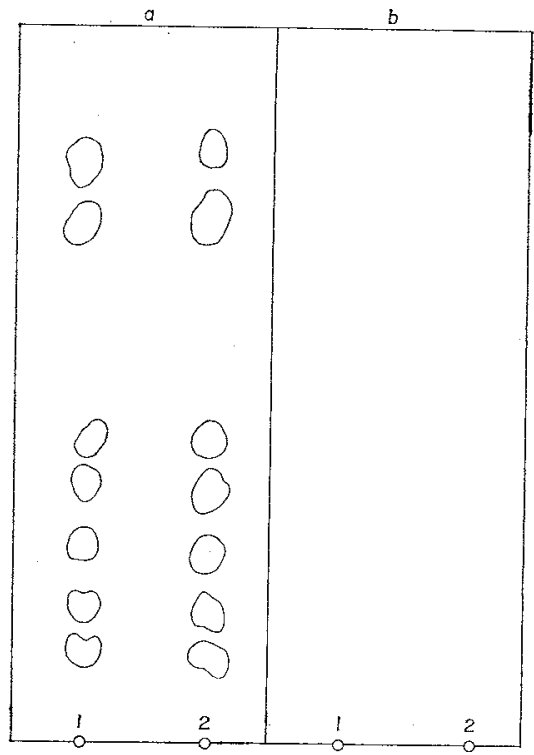

1. Acid hydrolysate of mycobacillin.

2. Acid hydrolysate of triacetyl derivative.

a. Sprayed with $0.2 \%$ ninhydrin in acetone containing $1 \mathrm{ml}$ glacial acetic acid per $100 \mathrm{ml}$.

b. Sprayed with $0.1 \%$ 2,4-DNP in ethanol containing $1 \mathrm{ml}$ conc. $\mathrm{HCl}$ per $100 \mathrm{ml}$.

Table 1 shows that the number of acetyl groups per mole of mycobacillin derivatives as prepared in the $\mathrm{pH}$-stat and in presence of pyridine catalyst are two and three respectively.

Biological Activity.

Table 2 shows the biological activity of mycobacillin and its acetyl derivatives against $A$. niger $\left(\mathrm{G}_{3} \mathrm{Br}\right)$ spores in presence and in absence of serum. Acetylation of the antibiotic at two tyrosine hydroxyl groups adversely affects the antifungal activity. The minimum inhibitory concentration (MIC) is $35 \sim 40 \mu \mathrm{g} / \mathrm{ml}$ whereas for mycobacillin it is only $15 \sim 20 \mu \mathrm{g} / \mathrm{ml}$. Interestingly the derivatives are not at all inactivated in presence of serum, if incorporated to the extent of $50 \%(\mathrm{v} / \mathrm{v})$ in the medium whereas mycobacillin is under identical condition inactivated by serum to more than 90\%. Triacetyl mycobacillin has almost the same biological activity as the diacetyl derivative and 
Table 1. Extent of acetylation of mycobacillin derivatives

\begin{tabular}{c|c|c}
\hline \multirow{2}{*}{ Acetylation by } & \multicolumn{2}{|c}{ Moles of O-acetyl/mole of mycobacillin derivative } \\
\cline { 2 - 3 } & Colorimetric analysis & Spectral analysis \\
\hline pH stat & 1.88 & 1.90 \\
Pyridine catalysed & 3.15 & 2.00 \\
\hline
\end{tabular}

Table 2. Minimum inhibitory concentration (MIC) of mycobacillin and its derivatives in presence and in absence of serum against $A$. niger $\left(\mathrm{G}_{3} \mathrm{Br}\right)$ spores

\begin{tabular}{l|c|c|c}
\hline \multirow{2}{*}{ Compound } & \multicolumn{2}{|c|}{ MIC $(\mu \mathrm{g} / \mathrm{ml})$} \\
\cline { 2 - 3 } & $\begin{array}{c}\text { In presence of serum } \\
\text { (A) }\end{array}$ & $\begin{array}{c}\text { In absence of serum } \\
(\mathrm{B})\end{array}$ & Ratio (A/B) \\
\hline Mycobacillin & $180 \sim 200$ & $15 \sim 20$ & 10 \\
Diacetyl derivative & $40 \sim 45$ & $35 \sim 40$ & 1.1 \\
Triacetyl derivative & $40 \sim 50$ & $40 \sim 45$ & 1.1 \\
\hline
\end{tabular}

its serum inactivation is also nil.

It is of interest to note that acetylation of hydroxyl groups, as reported by EBATA et al. grossly reduces the biological activity of siomycin $\mathrm{A}$, a peptide antibiotic ${ }^{12}$.

Acknowledgement

We wish to express our appreciation to Dr. N.K. SinHA and Dr. S.K. DAs of Bose Research Institute, Calcutta for their kind help.

\section{References}

1) MAJUmder, S.K. \& S.K. Bose: Mycobacillin, a new antifungal antibiotic produced by $B$. subtilis. Nature 181: $134 \sim 135,1958$

2) MAJUmder, S.K. \& S.K. Bose: Amino acid sequence in mycobacillin. Biochem. J. 74: 596 599, 1960

3) BANER JeE, A.B. \& S.K. BoSE: Amino acid configuration of mycobacillin. Nature 200:471, 1963

4) Sengupta, S. \& S.K. Bose: $\gamma$-Glutamyl and D- or L-peptide linkages in mycobacillin. Biochem. J. 121: 839 846, 1971

5) Baner JeE, N.; S.K. MAJUmder \& S.K. Bose: Some preliminary studies on the evaluation of mycobacillin for therapeutic use. Bull. Cal. School Tropical Med. 7: 35 36, 1959

6) MAJUMder, S.K. \& S.K. Bose: Isolation and homogeneity of mycobacillin. Arch. Biochem. Biophys.. 90: $154 \sim 158,1960$

7) Riordan, J.F. \& B.L. VAllee: Acetylcarboxypeptidase. Biochemistry 2: 1460 1468, 1963

8) Thompson, A.R.: Cited in Organic Analysis, Vol. II, pp. 56 58, 1954. Edited by J. Mirchell, Ir., I.M. Kolthoff, E.S. Proskaner \& A. Weissberger, Interscience Publishers, Inc., New York

9) Riordan, J.F. \& B.L. VAllee: O-Acetyltyrosine. Methods in Enzymology. XI: 570 576, 1967. Edited by C.H.W. Hirs; Academic Press, New York

10) Dakin, H.D. \& R. West: A general reaction of amino acids. I \& II. J. Biol. Chem. 78: 91 105, $745 \sim 756,1928$

11) Turner, R.A. \& G. Schmerzler; A new method for identifying C-terminal residues in peptides. J. Am. Chem. Soc. 76: 949 950, 1954

12) Ebata, A.M.; K. MiYazaki \& H. Otsuka: Studies on siomycin. IV. Acyl derivatives of siomycin A. J. Antibiotics 22: 506 507, 1969 